radioactive contamination into the daily lives of a large proportion of the population.

The radiation dosimetry in bone from bone-seeking radioactive isotopes is being studied in several centres, and practical confirmation is being obtained of the theoretical calculations which have been reported previously. The correlation of the dose received by the sternal marrow during irradiation treatment with the hæmatological findings in such sternal marrow samples is also being studied. Experiments are also reported which are designed to provide further confirmation of Dr. R. H. Mole's observations that the important factor in the production of radiation leukæmia is the dosage-rate rather than the total dose received.

Confirmation of the advantages of radiotherapy with megavoltage radiation is reported from centres all over the world, and the installation and calibration of such equipment necessitate a considerable amount of time being spent on the basic physical measurements which are necessary before the equipment can be put into routine use.

Instruments for the continuous integration and recording of solar erythemal ultra-violet radiation have been designed in Queensland, Australia. This equipment will be used in conjunction with a survey which is now being made of various aspects of the occurrence of skin cancer in an attempt to assess the chief factors causing skin cancer.

Work is also continuing in several centres on the response of tumours to irradiation in atmospheres of various concentrations of oxygen. The radiosensitivity of normal and of malignant cells alike has been found to be under the control of the concentration of dissolved oxygen in the immediate environment of the cell. The administration of oxygen under pressure aims at raising tissue oxygen tension and hence tumour sensitivity by supercharging the plasma with dissolved oxygen.

An interesting application of the Sandberg-Moore technique for detecting tumour cells in venous blood is reported from the Middlesex Hospital, London. In addition to samples of peripheral venous blood and of blood from veins draining the tumour, samples of hepatic vein blood were taken by trans-cardiac catheterization in order to assess the ability of the liver to clear tumour cells from the blood passing through it. The nine cases of gastro-intestinal cancer in which samples were taken from both portal vein and hepatic vein are of particular interest. Tumour cells (eertain or suspicious) were seen in eight cases in the portal vein and in only two in the hepatic. Though the numbers are small, they strongly suggest a very substantial filtration effect by the liver. Curiously enough, even in gastro-intestinal tumour, the peripheral blood appears to be more often positive than the hepatic vein, and though the numbers are again too small to be reliable, this would if confirmed suggest in the first place a substantial by-pass of the liver (perhaps by tumour cells passing up the thoracic duct) and in the second place that the lung is a very much poorer filter than the liver.

A group at Mount Vernon Hospital presents interesting findings on the deoxyribonucleic acid content of the nuclei of tumours, using micro-spectrophotometry of Feulgen-stained preparations. Of 100 carcinomata of the cervix uteri, 40 had modal values at or near the normal diploid value, and 32 near the tetraploid value. No clear relation between ploidy and degree of differentiation was noted, though adenocarcinomata had high figures and both of two tumours of mixed histology had very variable nuclear deoxyribonucleic acid with no defined mode. Limited observations on recurrent tumours suggest that high-count tumours are more resistant to radiation and that recurrences have a higher count than the original tumour. In tumours from women, the presence of the sex chromatin (the small body which represents the heterochromatin of the $X X$ chromosome pair in man and some other animals) can be roughly correlated with the degree of ploidy, being usually present in diploid and often double in tetraploid tumours.

\title{
OBITUARY
}

\section{Mr. E. W. B. Gill, O.B.E.}

Ernest Walter Brudenell Gill died on December 20 at Watlington, Oxon, after a long illness, at the age of seventy-six. Born in London, the son of a canon, educated at Bristol Grammar School and Christ Church, Oxford, where he was an Open College Exhibitioner in mathematics and later a Scholar, he took a first-class in physies in 1905, a B.Sc. degree in 1909, became University demonstrator in the Electrical Laboratory under Townsend, and a Fellow (1910) and later the domestic bursar of Merton College, Oxford.

During the First World War he served in the Royal Garrison Artillery and the Royal Engineers Wireless Intelligence, which took him to the Middle East. Afterwards he wrote a witty little book, "War, Wireless and Wangles". During the Second World War he again was in Intelligence and operational research. He was a co-inventor of 'window', metal foils dropped from planes so that our aircraft could not be located by enemy radar; he also worked on devices for guiding tanks. After the War he and an American representative interviewed the German scientists. He was surprised to find how little they had contributed to the war effort, some pretending that this was to save the world from destruction. A humorous account of his experiences, intended as a book, remains in the manuscript stage.

Gill's numerous scientific contributions cover a wide range of physical problems. With Pidduck he measured the ionization coefficient in helium. He discovered the effect of the electric field on the saturation current of tungsten emitters in valves and developed an ingenious method of determining the high-frequency conductivity and dielectric constant of the soil by measuring the ratio of the vertical and horizontal components of electric field and the phase angle between them. He investigated extensively electrodeless discharges in high-frequency electric fields, and observed that at very low gas pressure the starting potential becomes very small when a magnetic field applied perpendicular to it is of such value that electrons move through their orbit in a time equal to their periodic time (1937), an effect 
recently spectacularly demonstrated by Cutolo in Naples, who started a discharge a long distance from the transmitter of an electromagnetic beam. With me he found that in zero magnetic field the initial multiplicution of charges at low pressure is due to secondary electrons released from the walls of the glass vessel. He contributed greatly to our knowledge of static electrification, showed that frictional electricity is caused by contact potentials and found that by freezing-in charges in ice surrounded by water, potential differences of several 100 volts appear across the ice. Later he turned his fertile mind to the elucidation of the mechanism of the rise of sap in trees.
Gill was an outstanding Englishman, a gay character, modest, with an inborn sense of humour and a fund of excellent stories. $\mathrm{H}_{e}$ had the original mind of a young man coupled with the neat approach of a professional soldier. Debunking ("rebuking sin") was his hobby. Bocause of his independent judgment, his unfailing logic and his devastating remarks (often noted by the Press), he stepped quite often on people's toes. He never received the recognition he deserved either as a scientist or for his work in the administration of the University or as an Alderman of the City. He was a trusted friend and a devoted husband, who is survived by his wife, three sons and one daughter.
A. von Enget.

\section{NEWS and VIEWS}

\section{National Agricultural Advisory Service: W. Morley Davies}

Mr. W. Monley Davies has retired from his post of senior advisory officer in the National Agricultural Advisory Service. He attended the University of Birmingham, taking a degree in chemistry and botany. During the First World War he was engaged on the manufacture of explosives in British Dyestuffs, Ltd., Huddersfield. Afterwards, he went to Gonville and Caius College, Cambridge, as a research student and worked in the School of Agriculture under Prof. T. B. Wood and Arthur Amos, taking a research B.A. in 1922. At the same time, he also obtained the agricultural diploma. In September 1922 he was appointed head of the Department of Chemistry at the Harper Adams Agricultural College, and later, in 1924, was also appointed as advisory agricultural chemist to the West Midland Province. During that period, mainly in collaboration with the late Prof. G. W. Robinson, Prof. T. Wallace, Sir William Ogg and others, many of the methods now in use in the Soil Survey were developed. In 1946 he was appointed the first director of the East Midland Province in the newly constituted National Agricultural Advisory Service. He was appointed senior education and advisory officer in charge of all the science sections of the Service and stationed at headquarters in London in 1949. As chairman of the Land Restoration Committee and also of the Technical Advisory Conference on the Restoration of Opencast Coal Land, he piloted much work on the technical problems of restoring land to agriculture after it had beon subjected to mineral working. He was also a member of the Ironstone Advisory Committee appointed by the Ministry of Housing and Local Government. During the period at headquarters he was secretary of the Agricultural Improvement Council (England and Wales) and assessor for the Ministry of Agriculture on several of the committees of the Agricultural Research Council as well as on the Geological Survey Board.

\section{Dr. N. H. Pizer}

Dr. N. H. Przkr, who will succeed Mr. Morley Davies, has been regional soil chemist in the Eastern Region of Great Britain since 1946 and has been interested in soil conditions affecting root development and nutrition of crops, particularly those related to soil conformation and structure. Physical dofects such as compacted or structureless layers have been found to occur in many soils and to impede drainage, root development and root activity. Some are due to treatment of the soil and others are natural, and thoir effects on crops vary with season. Methods of dealing with these defects have been worked out with the farmer's concerned. Some defects have required drainage operations or cultivations to a suitable depth when the soil was dry, and others a combination of the two. Dr. Pizer has also worked on the amount and distribution of organic matter in soils under different systems of husbandry and the effects which very low levels of organic matter may have on tho physical condition of soils and their ease of working. Another of his interests has been the occurrence of trace-element deficiencies in crops and the development of methods of recognition and treatment. As a result of this work, copper deficiency was found to occur in cereals growing on many fen peat soils and on very light sandy soils previously reclaimed from heath. Yields of cereals were increased from a few cwt. an acre to more than $30 \mathrm{cwt}$. by the

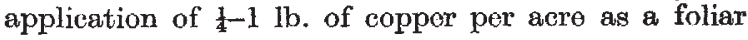
spray.

After the sea floods of 1953 which affected most of the coast-line of eastern England and extended inland up the river valleys, considerable work was done in the field and laboratory on methods of restoration of soils. Much variation was found between soils in the effects of salt on their physical condition, some being extensively damaged and others not at all, and these variations had an important influence on the treatment that was recommended to restore the land to its former condition. More recently, the problem of magnesium deficiency in fruit crops, glasshouse crops and arable crops on light land has been studied and practical methods of treatment developed.

\section{Paul Instrument Fund : Awards}

Awards of grants by the Paul Instrument Fund Committee have been made as follows: $£ 500$, in supplement of a previous grant, to Dr. B. V. Bowden, principal of the Manchester College of Science and Tochnology, for the devolopment of narrow pass-band dye filtors ; $£ 545$, in supplement of a previous grant, to Dr. R. Feinberg, of the Department of Electrical Engineering, Manchester College of Science and Technology, for the construction of an instrument for measuring the intensity of soft $\mathrm{X}$-radiation generated in experimental high-voltage valves; $£ \$ 3,000$ to Prof. 